\title{
Anomalous Concentration Dependence of Amorphous Curie Temperature and the Thermopower in Ternary $\mathbf{F e}-\mathrm{Cr}-\mathrm{B}$ Glasses
}

\author{
Z. PÁl AND A. LOVAS \\ Budapest University of Technology and Economics \\ Department of Vehicles Manufacturing and Repairing \\ Bertalan L. u. 2., 1111 Budapest, Hungary
}

\begin{abstract}
A non-monotonic compositional dependence of the amorphous Curie temperature $\left(T_{\mathrm{c}}^{\mathrm{am}}\right)$ and of the thermopower $(S)$ was found in $\mathrm{Fe}_{80-x} \mathrm{Cr}_{x} \mathrm{~B}_{15}$ glassy samples. The significant change in the slope of concentration dependence of both properties lead to the conjecture of a hidden structural change in amorphous state. Similar anomalies were also observed earlier in the concentration dependence of microhardness in the same glasses, which clearly contradicts to the traditional homogeneous single phase concept of glassy state. The results are interpreted on the basis of the existence of quenched-in phase reminiscences (clusters) in these alloys inherited from the liquid state.
\end{abstract}

PACS numbers: 71.55.Jv

\section{Introduction}

It was shown for the $\mathrm{Fe}-\mathrm{B}$ based glassy alloys [1] that replacement of $\mathrm{Fe}$ by non-magnetic $3 d$ transition elements lowers the $T_{\mathrm{C}}^{\mathrm{am}}$ and the mean ferromagnetic moments $\left(\mu_{\mathrm{Fe}-\mathrm{T}}\right)$. (This lowering effect does not significantly depend on the B-content.) It was also found out that the resulting change in $T_{\mathrm{C}}^{\mathrm{am}}$ and $\mu_{\mathrm{Fe}-\mathrm{T}}$ is not a linear function of the Cr content, but a discontinuity exists at around 4 at\% Cr content [2]. (Similar non-linear concentration dependence was observed for the thermopower $(S)$ in the same alloys.) The aim of this paper is to provide more experimental data concerning the Cr-concentration dependence of these properties, in order to facilitate the interpretation of this anomalous behaviour.

\section{Experimental: materials, equipment, and measurements}

The samples of the following compositions were used: $\mathrm{FeB}_{15}, \mathrm{FeCr}_{0.8} \mathrm{~B}_{15}$, $\mathrm{FeCr}_{1.6} \mathrm{~B}_{15}, \mathrm{FeCr}_{3} \mathrm{~B}_{15}, \mathrm{FeCr}_{4.5} \mathrm{~B}_{15}, \mathrm{FeCr}_{7} \mathrm{~B}_{15}, \mathrm{FeCr}_{8} \mathrm{~B}_{15}, \mathrm{FeCr}_{10} \mathrm{~B}_{15}$. The applied 
heat treatment parameters were: temperature of 250 and $300^{\circ} \mathrm{C}$ and duration of 1-15 h. Thermopower measurements were performed by touching the material surface with two contact points (made of copper) held at different temperatures and measuring the potential difference with a microvoltmeter. (Warm point is $3-7^{\circ} \mathrm{C}$ above room temperature, the cold contact point is stabilized at room temperature.) [3]. Vibration sample magnetometer was used for the determination of $T_{\mathrm{C}}^{\mathrm{am}}$.

\section{Results and discussion}

The sudden increase in microhardness (HV) was reported in the hypo-eutectic $\mathrm{Fe}-\mathrm{Cr}-\mathrm{B}$ alloys in the range of $0-3$ at\% $\mathrm{Cr}$ content. Simultaneously, the non-monotonic change of the crystallization enthalpy $(\Delta H)$ versus the $\mathrm{Cr}$ content was also observed around this concentration range [4]. The anomalous behaviour of $\mathrm{S}$ versus $\mathrm{Cr}$ content in the same composition range, is also visible in Fig. 1.

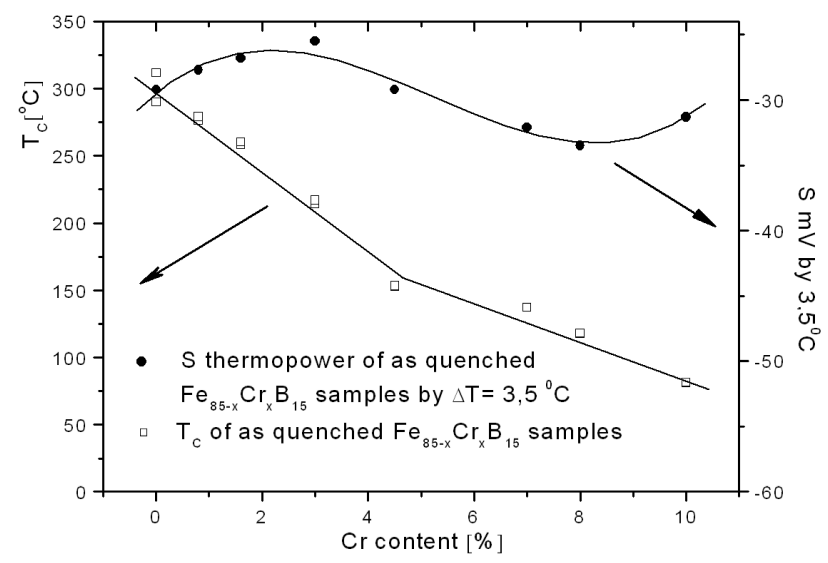

Fig. 1. The thermopower $(S)$ and the amorphous Curie temperature $\left(T_{\mathrm{C}}^{\mathrm{am}}\right)$ versus the Cr content for the as-quenched $\mathrm{Fe}_{85-x} \mathrm{Cr}_{x} \mathrm{~B}_{15}$ samples.

The $S$ shifts in opposite directions, below and above 4.5 at\% Cr content. From the trends of $S\left(C_{\mathrm{Cr}}\right)$ dependence the existence of a hidden structural change in amorphous state is suspected around this composition range based on the coexistence of stressed and compressed ("fcc" and "bcc") cluster types in these alloys which is inherited from the supercooled liquid [5]. In Fig. 1 the $T_{\mathrm{C}}^{\mathrm{am}}\left(C_{\mathrm{Cr}}\right)$ is also plotted. The change in the slope of concentration dependence is clear. In order to support this extraordinary $\mathrm{Cr}$ content dependence, $S$ was also measured using various temperature differences $(\Delta T)$. Selected data are collected in Fig. 2 for as-quenched and heat treated samples.

The influence of relaxation heat treatments. The thermopower can provide information about electronic structure, and it is less sensitive to structural changes. Surprisingly, the slight shift to negative values of $S$ was detected in the whole glass 

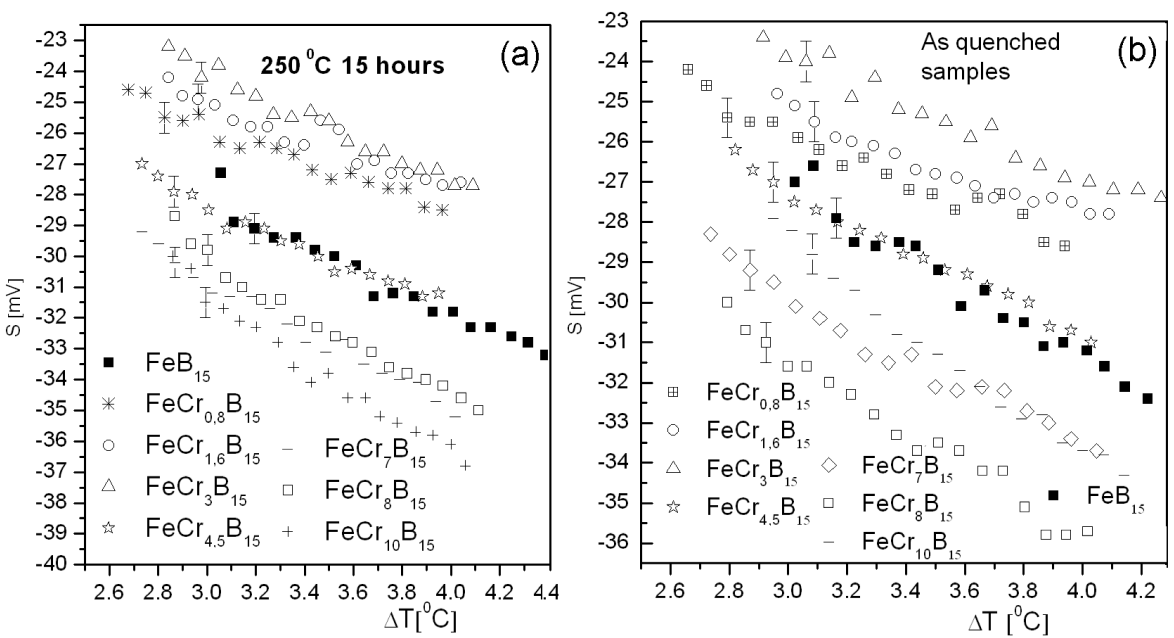

Fig. 2. $S$ versus $(\Delta T)$ dependence for the as-quenched (b) and heat treated (a) $\mathrm{Fe}_{85-x} \mathrm{Cr}_{x} \mathrm{~B}_{15}$ samples $\left(250^{\circ} \mathrm{C}, 15 \mathrm{~h}\right)$.

forming range for $\mathrm{Fe}_{100-x} \mathrm{~B}_{x}$ amorphous alloys due to structural relaxation [6]. This uniform shift turns to be more complex, when the Fe host metal is replaced by chromium. (See the points in the range 0.8-4.5 at\% $\mathrm{Cr}$ content.) The shift is positive in the diluted concentration range (between 0.8-4.5 at\% Cr content.) From the 4.5 at\% Cr content this tendency changes again.

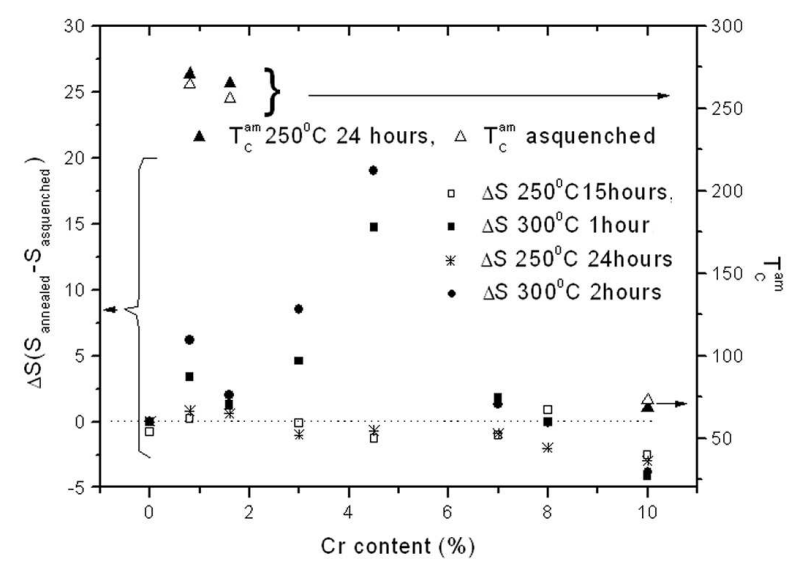

Fig. 3. The $\Delta S$ and the $T_{\mathrm{C}}^{\mathrm{am}}$ of the $\mathrm{Fe}_{85-x} \mathrm{Cr}_{x} \mathrm{~B}_{15}$ samples after heat treatments at $250^{\circ} \mathrm{C}$ for $15 \div 24 \mathrm{~h}$ and $300^{\circ} \mathrm{C}$ for $1 \div 2 \mathrm{~h}$.

One can assume that thermopower is a typical property which fits properly to the itinerant nature of the metallic electronic structure. As the $d$ electron density changes continuously when the host metal is gradually replaced by another transition metal such as the $\mathrm{Cr}$, the continuous change of $S$ is expected at constant 
temperature. Therefore, the sudden $S$ increase in the low concentration range of Cr content is surprising. Similar unexpected change in $S$ was found in NiZr based glassy alloys [7].

This anomaly seems to be of structural origin, which can be hardly explained on the basis of homogeneous continuum concept. The response of alloys to the structural relaxation is also remarkable. The change in sign of the shift is conserved during the relaxation heat treatments (see Fig. 3). The direction of $T_{\mathrm{C}}^{\mathrm{am}}$ shift $\left(\Delta T_{\mathrm{C}}^{\mathrm{am}}\right)$ is also positive below 4.5 at $\% \mathrm{Cr}$ after the annealing at $250^{\circ} \mathrm{C}$ for $24 \mathrm{~h}$, and negative for the alloy with $10 \mathrm{at} \% \mathrm{Cr}$ content after the same heat treatment. Therefore one can conclude that the $S$ and $T_{\mathrm{C}}^{\mathrm{am}}$ results do further support the assumption on the existence of a hidden structural change in amorphous state in this type of glasses.

\section{Conclusions}

Anomalous concentration dependence of thermopower and the amorphous Curie temperature was found in hypo-eutectic $\mathrm{Fe}-\mathrm{Cr}-\mathrm{B}$ glasses, which is also conserved after various structural relaxation heat treatments. There is a correlation between the sign of the shift of both quantities in the same concentration region. Based on this correlation, the existence of a hidden structural change can be suspected.

\section{Acknowledgments}

This work was supported by the Hungarian Scientific Research Fund (OTKA) through grants (No. T-046239) and the authors are grateful to Jozef Kovač (Slov. Acad. Sci.) for useful discussions.

\section{References}

[1] J. Kovac, L. Potocky, E. Kisdikoszo, Acta Phys. Slov. 35, 240 (1985).

[2] J. Kovac, L. Potocky, L. Novák, É. Kisdi-Kosz, Acta Phys. Slov. 40, 234 (1990).

[3] Z. Pál, J. Takács, in: 12th Int. Conf. on Applied Physics of Condensed Matter, Malá Lučivná (Slovakia) 2006, p. 348.

[4] A. Lovas, L.F. Kiss, F. Sommer, J. Non-Cryst. Solids 193, 608 (1995).

[5] D. Srolovitz, T. Egami, V. Vitek, Phys. Rev. B 24, 6936 (1981).

[6] L. Varga, A. Lovas, E. Zsoldos, C. Hargitai, B. Fogarassy, A. Cziráki, in: Proc. Conf. on Metallic Glasses; Science and Technology, Eds. C. Hargitai, I. Bakonyi, T. Kemény, Vol. 1, Distributor Kultura, Budapest 1980, p. 355.

[7] J. Tóth, I. Bakonyi, G. Hilscher, Europhys. Lett. 24, 379 (1993). 